Covered in: Web of Sciences (WOS); EBSCO; ERIH+; Google Scholar; Index Copernicus; Ideas RePeC; Econpapers; Socionet; CEEOL; Ulrich ProQuest; Cabell, Journalseek; Scipio; Philpapers; SHERPA/RoMEO repositories; KVK; WorldCat; CrossRef; CrossCheck

\section{Outdoor Education and its Influence on the Successful Involvement of Pupils in the Social Life}

\section{Henrietta TORKOS1, Anca Manuela EGERĂU²}

${ }^{1}$ University assistant, University of Aurel Vlaicu, Arad, Romania, torkos henriette@yahoo.com

${ }^{2}$ University lecturer, University of Aurel Vlaicu, Arad, Romania, anca_petroi@uav.ro
Abstract: One of the main priorities of current educational systems is a strong connection between education provided by schools and the requirements of a successful integration in the social life and work field. This article offers the teachers' perspective on the various ways in which outdoor learning can be useful in creating teaching-learning situations that prepare pupils to be active citizens and to have smoother integration in the social life and this way, on the labor market. The findings of a brief study among teachers from Arad County is presented. The method that was used is the survey based on a questionnaire. The main instrument that used was the questionnaire, which was based on a number of 12 variables. The quantitative data obtained was processed in the SPSS statistical program. The preliminary results show that even if teachers have some knowledge on the benefits of outdoor education regarding future involvement of pupils in social life, they tend to rarely use it in their educational practice. This happens because of the lack of correct and valid information they have on this type of education, and also because of the misconceptions of parents, who refuse to cooperate regarding this issue. The present study brings and important contribution in this research field, highlighting the values of outdoor education, both theoretically and practically.

Keywords: activities; education; labor; outdoor; social.

How to cite: Torkos, H., \& Egerău, A. M. (2020). Outdoor Education and Its Influence on The Successful Involvement of Pupils in The Social Life. Postmodern Openings, 11(4), 127-143. doi:10.18662/po/11.4/226 


\section{Introduction}

In a time of constant social change, education has to find new ways in order to prepare individuals to be inserted on the labor market and to be successful and active members of the society. The higher the levels of education, the wider is the range of positive outcomes of it, such as: better health systems, higher social trust, greater political interest and better intercultural relationships.

Education has its well-defined aims, which are usually reflected in individual benefits, such as: professional success, personal development, work security, financial and cultural prosperity. In societies, education aims at community equality and at the sense of social responsibility and communication, in order to fit in the educational activities and the moral of good citizenship.

The importance of the present article in the postmodern education and recent studies, is to enhance the relevance and the benefits of outdoor education in times of constant social and educational change, as being part of the new education types. Research have shown outdoor education to have positive impact on pupil's development, regarding emotions, communication competencies and physical activity (Loynes, 2002). Physical inactivity may be considered as a risk for the modern generation of pupils. (Bailey, 2000). Even if many children seem to adapt to a high degree of physical inactivity, it may have temporary and also future negative effects to adapt to surroundings that are different to abstract learning strategies (Bjorklund \& Bering, 2000).

Also, in terms of active citizenship and a smooth introduction on the labor market, education regarding industry aims individuals to prepare for employment, through the development of literacy skills, numeracy, and lately also the development of transversal competencies. The objectives of education are long term aspirations, so they can only be achieved in a long period of time, and also some of them can be seen also as lifelong experiences.

The most recent studies show that taking pupils of all ages outside the classroom, can offer different benefits, like the possibility to learn more directly and less abstractly, and to be more physically active. This may lead to numerous behavioral benefits (Dyment, 2005; Dyment \& Bell, 2008), regarding social skills, emotional wellbeing (Ozdemir \& Yilmaz, 2008; Russell \& Newton, 2008) and some of the most important key learning ones (Smith \& Motsenbocker, 2005). 


\section{Literature review}

\subsection{An objective overview on outdoor education}

From an etymological point of view, outdoor education refers to a situation of organized learning, which takes place in the outdoor environment. Outdoor education activities can also involve experiences based on travel in the immediate environment, by participating in a variety of adventures and outdoor activities, such as hiking, climbing, boating, rope racing or even group games that are organised and have specific objectives.

The concept of outdoor learning focuses on an education type that is based on experience and practical activities that can take place outside the classroom, and which objectives are to understand oneself and the society. It is a relatively new type of education in Romania, producing long-lasting effects in terms of mastering complex learning situations and especially the development of skills necessary for modern life: innovation, leadership, team spirit, communication, autonomy and creativity.

From the social point of view, Neill (2001) gives a personal note to the definition of outdoor education using the term outdoor education for instructive educational activities that are designed intentionally, having as common philosophy the formation and growth of the individual by placing him in challenging situations, using natural spaces. Also, outdoor education is defined as a phenomenon of postmodern Western society. It does not take place as we currently understand and define it in Eastern society or in pre-modern Western society. It is necessary to distance oneself from the civilization, for nature to have new effects and to stimulate learning, so outdoor education to be considered worthy of identification. (Neill, 2004)

\subsection{Conceptual landmarks in education for society}

Education for society is a compulsory subject in the curricular area of social humanistic education and aims to develop in students the skills for a democratic culture. The curriculum focuses on the individual, with its particularities and needs, its own pace of learning, its development and also on the assumption of values such as: democracy, human rights, the rule of law and cultural diversity.

The basic concepts of education for society as scholar subject, represent a set of concepts which contribute to the formation of a set of skills required in a culture of democracy, consisting of: values, attitudes and critical knowledge. The preschool and primary school curriculum aims the formation of skills for a culture of democracy, capitalizing on the following concepts: 
- identity;

- diversity and pluralism;

- responsibility;

- conflict and communication;

- rules and law; governance;

- equality; rights and freedoms;

- media.

The curriculum also proposes the debate of current topics and it includes: radical views, corruption and integrity, false news, citizenship in the online environment, propaganda and manipulation, citizens' apathy to get involved in public and political life.

Skills for a democratic culture are developed through focused approaches on the learning process, as well as through approaches focused on the learning contents. Through approaches focused on the learning process we mention: modelling in a democratic way of attitudes and behaviours, democratic organization of processes in the classroom, learning through cooperation and also project-based learning.

The interrelated application of these approaches helps students become young citizens who:

- know buman rights and freedoms and understand the conditions / factors on which they depend (learning on democracy and human rights);

- have the experience of the class / school as a micro-society that respects the freedoms and equality of its students and are prepared to exercise their rights and to respect the rights of others (learning through democracy and human rights);

- are able and confident to exercise their rights, with a mature sense of responsibility towards others and their community (learning for democracy and buman rights). (Ministry of Education, Culture and Research of the Republic of Moldova, 2018)

\section{Recent perspectives}

Recent research highlights the multiple benefits of outdoor education and its components, as various outdoor activities can be combined with adventures or excursions, even camping. The relationship between students engaged in activities focused on outdoor education and teachers, is improving, and as a result, many cultural connections are becoming possible. Various health benefits have been observed, both physically and mentally. During these activities, children develop managerial skills and competences, as they can find positive role models, they can learn 
to develop leadership opportunities, they can look for personal development methods individually and, especially from a social point of view, they can develop friendships, connect with each other and learn from each other. Through these activities, there is the opportunity to develop responsibility and independence, to enhance inter- and intra-personal skills, active involvement, problem solving and the development of decision-making skills. (Hattie et al., 1997)

Transversal competencies represent value acquisitions and attitudes that go beyond a certain field or study program, and are expressed through the following descriptors: autonomy and responsibility, social interaction, personal and professional development. (Ilica, 2013) These are the capabilities that transcend the specialization of public policy and program evaluation, having a transdisciplinary nature: teamwork skills, oral and written communication skills, respect and development of professional values and ethics, IT use, problem solving and decision making, recognition and respect for diversity and multiculturalism, learning autonomy, initiative and entrepreneurship, openness to lifelong learning, etc. (Stevahn et al., 2005)

Transversal competencies provide: teamwork skills, oral and written communication skills in the mother tongue and foreign languages, reasoning skills, argumentation and critical thinking, use of information and communication technology - ICT, problem solving and decision making, recognition and respect for diversity and multiculturalism, learning autonomy, initiative and entrepreneurship, openness to lifelong learning, respect for and development of professional values and ethics, skills to operate in an interdisciplinary manner with methodologies and concepts from the field of exact sciences, socio-human sciences and artistic creation, etc. The outcomes of outdoor education differ between groups of children. For some children the outcomes are crucial to avoid behavioral problems. The group of children that is not at risk of developing behavioral problems, can get short time benefits from outdoor education, with an increased vitalizing, involving more physical activity, more differences in emotions and even more positive communication. (Cowen \& Durlak, 2000; Durlak \& Wells, 1997; Fox \& Avramidis, 2003; Whitty, 2006)

Also, one of the main attitudes that can be developed through education is global civic spirit, which can be explained by openness and awareness, tolerance and respect for diversity, responsibility and ability to resolve conflicts, ethical and intercultural understanding, democratic participation, respect for the environment, national identity and sense of belonging, ability to critically evaluate information and media content and 
the ability to obtain and analyse information through computerized and technological tools.

\subsection{Social education approach through outdoor learning}

In the review of the new theoretical frameworks for transversal competences that outdoor learning can develop, it was found that one of the major challenges in integrating transversal competences in education is their use in existing curricula. The second challenge is to select the skills that need to be developed, as they differ in importance and value to learners. Also, some transversal competences already exist in the curriculum and require only a terminological reformulation. (Trier, 2003)

Outdoor education is a learning model based on the experience and direct activity of students with natural elements, curricular contents and human resources, in a natural, free, unconstrained environment, in which communication skills, socialization, autonomy, and responsibility can be developed more efficiently and quickly than through any other form of education. Outdoor education is a form of experiential education that can develop transversal skills that are often discussed in modern educational systems, and provided in contemporary education policies all around the world.

As we have presented it in another study, regarding the social aspects of outdoor learning, complexity of today's society requires that educational systems, through the instructive-educational activities they organize, develop individuals prepared for social life but also for a satisfying personal life. This can only become possible if the learner goes through situations that can shape him physically, socially and mentally. Education can achieve this by organizing activities, in which students can practice cohesion, cooperation, respect, self-respect, self-discipline and care for the well-being of others. Outdoor education is a way to practice these behaviours within the frames of formal education. (Torkos, 2017)

The system is based on challenges and tasks, developing an innovative curiosity, invincible will, tenacity and compassion. Outdoor education encourages children to develop in all three stages: physically, emotionally and mentally, helping to understand and protect the local environment and leading to social development. It also stimulates exploration, decision-making and playing, having a non-formal character and following visible changes in the behaviour and attitude of the participants. It is based on personal experiences, such as learning and socializing. (Banning \& Sullivan, 2011) 
In outdoor education, students have the opportunity to develop their imagination, vocabulary and certain social skills. Collaborative activities develop those transversal skills that mostly have a social character. By encouraging children to investigate, ask questions, and find solutions, they begin to trust their own ideas. In the classrooms, each object has its own place and role, meeting the needs of each student, at any age. All the more, so as the resources found in nature, provoke learning experiences through their variety. (Blanchard \& Buchanan, 2011)

\section{Rsearch design}

The research of the present article was based on the method of survey. The main instrument used was the questionnaire. This instrument was applied, with the purpose of collecting data regarding the opinions, knowledge and experiences of teachers from Arad county, on the concepts of outdoor learning and social education.

The questionnaire was based on personal and identifying information of the teachers that have participated in the study, educational experience, gender, age, the environment in which they profess and the specialization they have, and also their knowledge and attitude on the combination of outdoor learning in accordance with social education, and skills that can be developed, in order to motivate better adaptation in the social life and on the labour market.

The items were elaborated maintaining the same structure of the objectives, using different scales. The first items refer to the familiarity with the concepts. The next set of items is concerned about the rate in which both types of education are used within primary and preschool classes. The questionnaire ends with questions related to limitations. We wanted to offer a realistic image on the availability of the teachers to overcome in organizing outdoor activities in completion to social education, or to choose to be mere spectators in the instructional-educational process.

There were 88 participants, primary school and preschool teachers, also a few special education teachers. There was used a convenience sample, where participants were selected based on naturally occurring groups. Also, there were limitations of the study, regarding the fact that the subject is still new in the Romanian literature. Also, in terms of statistical relevance of the data that was gathered, the research utilized convenience sampling technique, as the purpose of this investigation is explorative. The total number of 88 participants was consecutively selected according to the order of appearance, when completing the online questionnaire, that was shared 
on social media platforms, according to the convenient accessibility principle.

\subsection{Objectives of the study}

One of the main objectives of the study, was to find out, at what extent can outdoor education develop social competencies in preschools and primary schools from Arad county.

The secondary objective of the study was to find out the openness of teachers, regarding the use of outdoor learning activities in their daily routines.

The participants were randomly chosen, because if they would participate on the desire criteria, the results of the study could have been altered. The quantitative data that has been collected in the period of 03.03.2019 and 03.04.2020, was introduced in the SPSS 6.0 statistical program for analysis.

\subsection{Methodology}

Through the questionnaire-based survey, the study desires to analyse the knowledge of 88 teachers in relation with the use of outdoor learning activities as the main developer of social education elements. The main instrument used was the questionnaire. This tool was developed by the authors, and was applied, with the purpose of collecting data regarding the opinions, knowledge and experiences of teachers from Arad county, regarding the concepts of outdoor learning and social education.

In order to verify the validity of the scales used, fidelity analyses were performed for the main instrument used in the study, on a number of 13 out of 15 items. This was important to specify, because of the validity of the questions used in the questionnaire regarding the subject of interest of the research.

The questionnaire related to outdoor education in connection with education for society, has got the following score. $(\alpha=, 710)$. The analysis was performed on the majority of the items. The minimum mean was $\mathrm{M}=$ 4.41 and the maximum standard deviation was within the knowledge criterion, $\mathrm{SD}=3,847$. (Table 1 ) 
Table 1. Fidelity analysis of the questionaire

\begin{tabular}{|c|c|c|}
\hline \multicolumn{3}{|l|}{ Fidelity } \\
\hline \multicolumn{3}{|c|}{ Cronbach's } \\
\hline \multicolumn{3}{|c|}{$\begin{array}{c}\text { Alpha Based } \\
\text { on }\end{array}$} \\
\hline Cronbach's & Standardized & \\
\hline Alpha & Items & $\mathrm{N}$ of Items \\
\hline ,71 &, 789 & 13 \\
\hline
\end{tabular}

Source: Authors' own conception

Of the 15 items of the questionnaire, 5 represent identification variables, 10 items give teachers the opportunity to select answer options, giving the possibility to perform a clear and relevant statistical analysis. The confidence level is $89 \%$ with a $21 \%$ margin of error on the population that was used throughout the study.

Out of the total number of surveyed teachers, $42 \%$ carry out their instructive-educational activity in rural areas, and 58\% in urban areas.

Compared to the age category of the teachers who participated to the present study, there was a significant variation:

- $28 \%$ of teachers are aged between $19-25$ years

- $20 \%$ are aged between $26-35$ years

- $34 \%$ are ages between 36-45 years

- $9 \%$ between 46-55 years and

- $9 \%$ between 56-61 years.

\section{Research findings}

The collected data was introduced as quantitative data in the SPSS statistical program, in order to analyze and conclude on the results. There were used both parametric and non-parametric statistical tests in order to get to the results. Correlations were analyzed between the extent of outdoor learning activities use and between the existence of social elements within the classes in which the participant teachers work. Also, correlations were analyzed between the age and experience of teachers and the way in which they use outdoor learning activities in order to develop social competencies and democratic attitudes. Also, we have analyzed if there were positive correlations between the level of social adaptability and the level of outdoor learning activities used in class. The finding of the research shows the following: 
Table 2. Distribution of participants by specialty

\begin{tabular}{lc}
\hline \multicolumn{1}{c}{ Specialty } & Participants \\
Primary school & 30 \\
Preschool & 30 \\
Special education field & 28 \\
\hline
\end{tabular}

Source: Authors' own conception

Within all partipants, a number of 30 teachers are working in primary schools, and an even number of teachers work in preschools. A number of 28 respondents, state that they work as special education teachers. A number of 6 answers, could not be taken into consideration, because of some technical issues regarding the completion of the questionnaire and also because of the negative first answer, as they couldn't continue with the completion of the questionnaire.

Regarding the identification of the form of employment in the education system of the participants, we have found that $72 \%$ have concluded employment contracts with the educational units in which they work indefinitely, $18 \%$ have as a form of employment a determined period, and $10 \%$ are employed by the hourly payment.

As about the question that refers to the seniority in education, it was found that $25 \%$ of the teachers who completed the questionnaire have less than 5 years old in the educational field, 35\% have 6 to 10 years, $25 \%$ have a seniority in education between 11-20 years, and 15\% have a seniority of over 20 years in education.

The first question concerned about the level of knowledge regarding the concept of outdoor education in schools, and the result are presented as it follows:

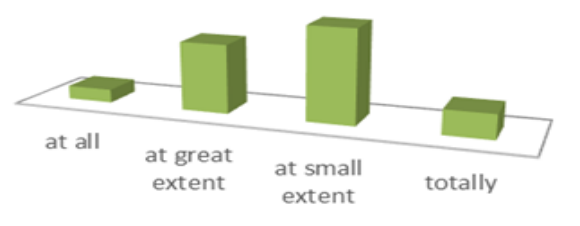

Figure 1. The level of knowledge on outdoor learning concept

Source: Authors' own conception

As it can be seen from the graphic presented above, the large majority of participant teachers admit they know little about the concept of outdoor education. A similar number of teachers, 31, admit they have 
knowledge on the concept at great extent. Only a number of 11 participants state they are totally familiar with the concept.

The second question which was about the way in which the participants got into contact with the concept, the answers are as it follows:

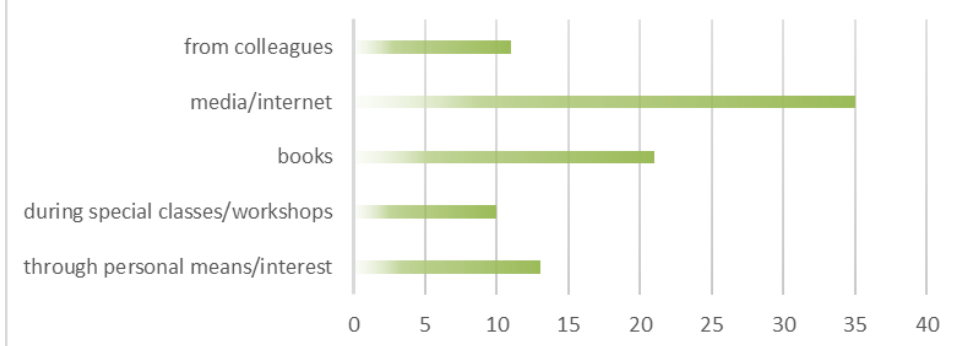

Figure 2. Ways of getting into contact with outdoor education concept

Source: Authors' own conception

As the graph above shows it, most of the participant teachers have gotten into contact with the concept by instruments belonging to media or internet. Unfortunately, the smallest percent of teachers have known or heard of outdoor education by participating to special classes or workshops organized for this aim. This raises concern, for all the institutions that organize activities for teachers and teachers to be, because outdoor education is an area of interest that still needs to be exploited.

The third question was about the second concept of interest, education for society and elements that ease social adaptability and community integration. The participants responded as it follows:

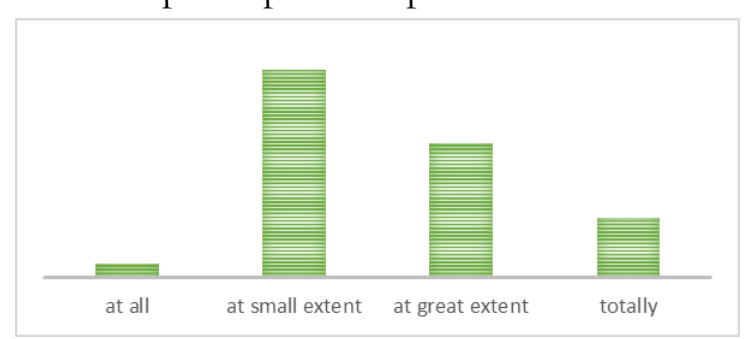

Figure 3. Level of knowledge on education for society concept

Source: Authors' own conception

Analyzing the results, we have noticed that the answers are similar to the first question used in the research. Participants state that they have similar knowledge on both concepts.

The next question supposed to be analyzed in the present article, was weather the teacher participants trust that outdoor education can develop 
competencies needed for better social integration and adaptability on the labor market. The responses are presented in the following graph:

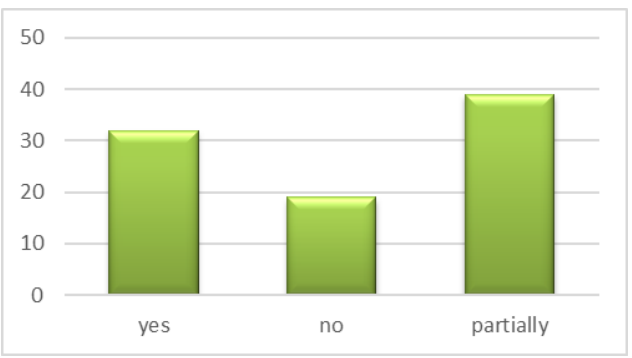

Figure 4. Trust regarding $\mathrm{OE}$ and development of social competences

Source: Authors' own conception

There have been noticed a positive correlation between those participants who use $\mathrm{OE}$ activities during classes and those who have answered positively at the question regarding trust towards the development of social skills.

Table 3. Positive correlation between use of OE and trust in the development of social skills

Independent Samples Test

95\% Confidence Interval of the Difference

\begin{tabular}{|c|c|c|c|c|c|c|c|c|c|}
\hline \multirow{2}{*}{\multicolumn{2}{|c|}{$F$}} & \multirow[b]{2}{*}{ Sig. } & \multirow[b]{2}{*}{$\mathrm{t}$} & \multirow[b]{2}{*}{ df } & \multicolumn{2}{|c|}{ Sig. (2- Mean } & \multicolumn{2}{|c|}{ Error } & \multirow[b]{2}{*}{ Upper } \\
\hline & & & & & tailed) & Difference & Difference & Lower & \\
\hline \multirow[t]{2}{*}{ TotalOEComp } & $\begin{array}{l}\text { Equal variances 7,605 } \\
\text { assumed }\end{array}$ &, 011 & 8,9 & &, 000 & 6,089 & ,683 & 4,697 & 7,491 \\
\hline & $\begin{array}{l}\text { Equal variances } \\
\text { not assumed }\end{array}$ & & 9,4 & 26 & 1,000 & 6,079 & ,646 & 4,762 & 7,416 \\
\hline
\end{tabular}

\section{Source: Authors' own conception}

Another important question that has to be analyzed, is the set of competencies and skills teachers have noticed to be developed following the use of outdoor learning activities during their instructive educational routines. The answers are represented in the following graph: 


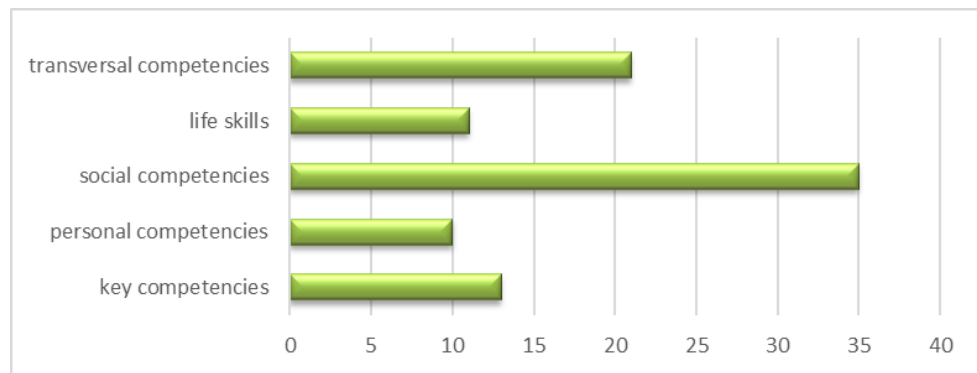

Figure 5. Set of skills and competencies developed through outdoor education activities within respondents that used OE in class at the level of preschool, primary school and special education institutions

Source: Authors' own conception

The majority of answers are directed towards social competencies and transversal competencies. Both categories contain similar elements and are directed towards the same structure. Key competencies were the third most chosen answer, and an almost equal number of participant teachers, have experienced the development of personal competencies and life skills through outdoor education activities within class.

The following step is to analyze the specific answers of teachers regarding which competencies/skills are developed the most through OE, from those in the category of social adaptation and successful involvement in the community and more specifically on the labor market. The short answers are presented as it follows:

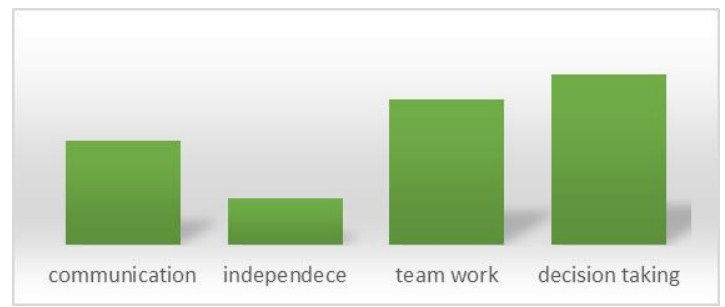

Figure 6. Transversal competencies and social skills most often developed by the use of $\mathrm{OE}$

Source: Authors' own conception

The graph presented above, shows clearly the 4 most chosen elements that teachers who participated to the present research have considered to be developed by using outdoor education. Decision taking and team work were the most used answers, closely followed by communication and independence. 
The last question of interest that we analyze in this paper, from all those introduced in the questionnaire, is teacher's opinion on the issue of adapting $\mathrm{OE}$ in the daily routine of preschoolers, primary school pupils and to special educational needs. The answers are presented in the following graph:

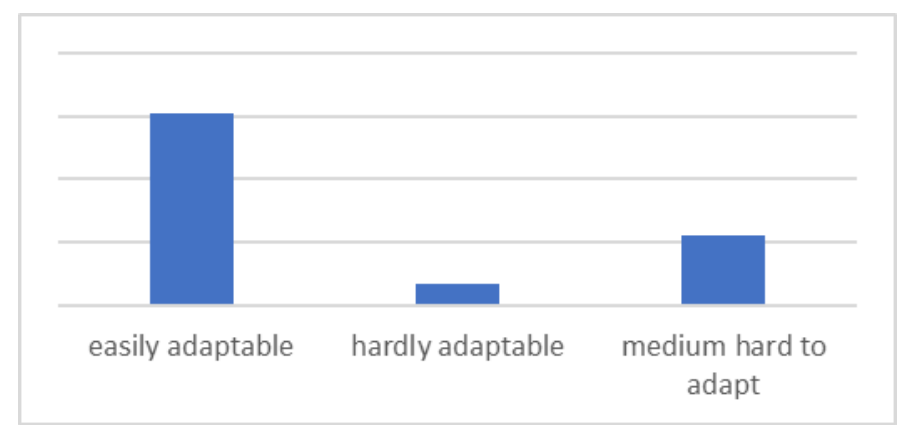

Figure 7. Teachers opinion on the difficulty level of adaptation OE to different kind of school levels

Source: Authors' own conception

The answers show the openness of teachers to adapt outdoor learning activities to curricular contents. Most of the positive answers were collected from teachers that work in the special educational institutions. This prove that outdoor education can be used as a great teaching-learning tool to develop social competencies for pupils with social educational needs, in order to ease their adaptation in the community and later on, on the work field.

\section{Conclusions}

The present article, through its theoretical frame and its practical outcome, brings an insight on the situation of pedagogical elements that outdoor learning brings in the educational field of Arad county regarding social involvement and democratic citizenship, in terms of successful integration on the labor market of pupils. The overall results show the importance of introducing outdoor learning activities in formal education, in order to develop social skills at the level of group cohesion, self-esteem, selfdiscipline, taking care of others and creating a better social climate. Deepening within the other phenomena studies, that show the same results or similar ones to those presented in this study, appear the possibility to achieve through holistic exploration, a training of the valences of outdoor education, independent of the valence of the development of some 
competences. The role of adults, the assignment of teachers, as well as the active involvement of parents in all activities related to outdoor education, favor the new directions discovered in this regard. (Cunningham, 2006; Gill, 2007; Guldberg, 2009; Ozga, 2005; Robson \& Hunt, 1999).

One of the most genuine preoccupations of the human community and of the educational systems throughout the world, is to create adaptable members of the society, through education, and this can be possible through the correct use of the learning tools that develop certain, but also holistic competencies.

\section{References}

Bailey, D. (2000). Is anyone out there listening? Quest, 52(4), 344-350. http://dx.doi. org $/ 10.1080 / 00336297.2000 .10491721$

Banning, W., \& Sullivan, G. (2011). Lens on outdoor learning. Redleaf Press

Bjorklund, D. F., \& Bering, J. M. (2000). The evolved child - Applying evolutionary developmental psychology to modern schooling. Learning and Individual Differences, 12(4), 347-373. http://dx.doi.org/10.1016/S1041-6080(02)00047-X

Blanchard, P. B., \& Buchanan, T. K. (2011). Environmental stewardship in early childhood. Childhood Education, 87(4), 232-238. https://doi.org/10.1080/ $\underline{00094056.2011 .10523184}$

Cowen, E. L., \& Durlak, J. A. (2000). Social policy and prevention in mental health. Development and Psychopathology, 12(4): 815-834. https://doi.org/10.1017/ $\underline{\mathrm{s} 0954579400004132}$

Cunningham, H. (2006). The invention of childhood. BBC Book.

Durlak, J. A., \& Wells, A. M. (1997). Primary prevention mental health programs for children and adolescents: A meta-analytic review. American Journal of Community Psychology, 25(2), 115-152. https://doi.org/10.1023/a:10246540 $\underline{26646}$

Dyment, J. E. (2005). Gaining ground: The power and potential of school ground greening in the Toronto District School board. http://www.evergreen.ca/ docs/res/Gaining-Ground.pdf

Dyment, J. E., \& Bell, A. C. (2008). Grounds for movement: green school grounds as sites for promoting physical activity. Health Education Research, 23(6), 952962. http://dx.doi.org/10.1093/her/cym059

Fox, P., \& Avramidis, E. (2003). An evaluation of an outdoor education programme for students with emotional and behavioural difficulties. Emotional and Behavioural Difficulties, 8(4), 267-283. https://doi.org/10.1080/ $\underline{13632750300507025}$ 
Outdoor Education and Its Influence on The Successful Involvement of Pupils ... Henrietta TORKOS, Anca Manuela EGERĂU

Gill, T. (2007). No fear. Growing up in a risk averse society. Calouste Gulbenkian Foundation.

Guldberg, H. (2009). Reclaiming childhood freedom and play in an age of fear. Routledge.

Hattie, J. A., Marsh, H. W., Neill, J. T., \& Richards, G. E. (1997). Adventure education and outward bound: Out-of-class experiences that have a lasting effect. Review of Educational Research, 67(1): 43-87. https://doi.org/10.3102/ $\underline{00346543067001043}$

Ilica, A. (2013). Discurs pedagogic contemporan [Contemporary pedagogical discourse] Editura Chişinău.

Loynes, C. H. (2002). The generative paradigm. Journal of Adventure Education and Outdoor Learning, 2(2). 113-125. https://doi.org/10.1080/14729670285200221

Ministry of Education, Culture and Research of the Republic of Moldova. (2018). Curriculum de educatie pentru societate [Curriculum for social education]. http://particip.gov.md/public/documente/137/ro 5366_EducatiaPentruS ocietateGimnaziu2018-05-25.pdf

Neill, J. T. (2001). A profile of outdoor education programs and their implementation in Australia. Japanese Outdoor Education Journal, 5(2), 1-9. https://doi.org/10.11317/joej1997.5.2 1

Neill, J. T. (2004). Whose journeys? The outdoors and adventure as social and cultural phenomena: Critical explorations of relations between individuals, 'others' and the environment. Humberstone, Brown, \& Richards.

Ozdemir, A., \& Yilmaz, O. (2008). Assessment of outdoor school environments and physical activity in Ankara's primary schools. Journal of Environmental Psychology, 28(3), 287-300. http://dx.doi.org/10.1016/j.jenvp.2008.02.004

Ozga, J. (2005). Modernising the education workforce: A perspective from Scotland. Educational Review, 57(2): 207-219. https://doi.org/10.1080/ $\underline{0013191042000308378}$

Robson, M., \& Hunt, K. (1999). An innovative approach to involving parents in the education of their early years children. International Journal of Early Years Education, 7(2), 185-93. https://doi.org/10.1080/0966976990070206

Russell, W. D., \& Newton, M. (2008). Short-term psychological effects of interactive video game technology exercise on mood and attention. Educational Technology \& Society, 11(2), 294-308. https://www.researchgate. net/publication/220374849 Short-

Term Psychological Effects of Interactive Video_Game Technology E xercise on_Mood and Attention

Smith, L. L., \& Motsenbocker, C. E. (2005). Impact of hands-on science through school gardening in Louisiana public elementary schools. Horttechnology, 15(3), 439-443. https://journals.ashs.org/horttech/view/journals/horttech $\angle 15 / 3 /$ article-p439.pdf 
Stevahn, L., King, A. J., Ghere, G., \& Minnema, J. (2005). Establishing essential competencies for program evaluators. American Journal of Evaluation, 26(1), 43-59. https://doi.org/10.1177/1098214004273180

Torkos, H. (2017). Social and psychological aspects of outdoor education. Agora Psycho-Pragmatica, 11(1), 215-223. https://www.uav.ro/jour/index.php/ app/article/view/801

Trier, U. (2003). Twelve countries contributing to DeSeCo: A summary report. In D. Rychen, L. Salganik \& M. McLaughlin (Eds.), Definition and selection of key competences. Contributions to the second DeSeCo symposium (pp. 7-59. 320). Swiss Federal Statistical Office.

Whitty, G. (2006). Education(al) research and education policy making: Is conflict inevitable?. British Educational Research Journal, 32(2), 159-176. https://doi. org/10.1080/01411920600568919 